\title{
DEMOCRACIA, AUTORITARISMO E IMPERIALISMO: a centralidade da agenda conservadora na política brasileira
}

\author{
Ilse Gomes Silva \\ Universidade Federal do Maranhão (UFMA)
}

DEMOCRACIA, AUTORITARISMO E IMPERIALISMO: a centralidade da agenda conservadora na política brasileira Resumo: O artigo problematiza o processo de crescimento da direita no Brasil, a hegemonia da agenda conservadora no cenário político e as fragilidades da democracia brasileira. Considera que, na atualidade, a cena política está marcada pelo crescimento da presença de amplos setores da direita nas ruas, disputando o apoio da população para os seus temas conservadores e autoritários. Argumenta que essa direita tem demonstrado força e tem pautado o debate político ancorada no resultado das eleições de 2014 que conferiu ao Congresso Nacional e às políticas governamentais um caráter conservador e autoritário que coloca em discussão o exercício da democracia no Brasil.

Palavras-chave: Democracia, autoritarismo.

DEMOCRACY, AUTHORITARIANISM AND IMPERIALISM: the centrality of the conservative agenda in Brazilian politics Abstract: The article discusses the process of growth of the right wing in Brazil, the hegemony of the conservative agenda in the political scene and weaknesses of Brazilian democracy. Considers that, nowadays, the political scene is marked by the growth of the presence of large sectors of the right wing in the streets, disputing for popular support for its conservative and authoritarian themes. Argues that this right has shown strength and has guided the political discussion anchored in the results of the 2014 elections which gave to Congress and government policies a conservative and authoritarian character that calls into question the exercise of democracy in Brazil.

Key words: Democracy, authoritarianism. 


\section{INTRODUÇÃO}

Paraná, 29 de abril de 2015, na Praça Nossa Senhora da Salete, em frente à Assembleia Legislativa, um protesto dos professores da rede estadual de ensino, em greve ${ }^{1}$ desde 09 de fevereiro, juntamente com os servidores públicos, contra o projeto de lei que muda a previdência dos servidores públicos é duramente reprimido pela polícia militar, resultando em mais de 200 feridos. O campo de guerra montado pelo governador Beto Richa do Partido da Social Democracia Brasileira (PSDB) e o tamanho da violência contra professores e servidores provocaram indignação nacional e repercussão internacional.

Nesse episódio também chama atenção a simbiose entre os poderes Executivo, Legislativo e Judiciário para garantir a repressão ao movimento dos professores e impedir a negociação da pauta de reivindicação. O judiciário prontamente decretou a ilegalidade da greve e puniu o Sindicato dos Trabalhadores em Educação Pública e seu presidente com multas altíssimas por dias parados. O legislativo proibiu a presença dos professores no plenário da Assembleia Legislativa e, enquanto professores sofriam com as bombas de gás lacrimogêneo, balas de borracha e spray de pimenta, garantiu a aprovação do projeto de Lei que muda a previdência, encaminhado pelo governador.

As imagens registradas da violência dos policiais contra os professores e dos feridos são profundamente impactantes e nos fazem lembrar as cenas da ditadura civil militar de 1964 e nos perguntarmos que tipo de democracia estamos vivendo no Brasil do século XXI. O que ocorreu com os professores do Paraná não é um caso isolado do governo do PSDB, a esse fato podemos acrescentar os assassinatos de lideranças sindicais no campo, os conflitos fundiários, a truculência da polícia de pacificação nas favelas, a violência contra o Movimento do Passe Livre (MPL). A violência somente não foi registrada nas manifestações da direita que ocorreram durante o ano de 2015, em uma clara demonstração de que a atuação da polícia é seletiva e direcionada às classes trabalhadoras.

Esses registros de violência do aparato repressor do Estado brasileiro constituem o padrão de atuação dos governos e que tem se intensificado nos últimos anos com o crescimento do número de manifestantes nas ruas reivindicando melhores condições de vida e de trabalho. Entretanto, na mesma medida em que cresce a violência policial, cresce também o movimento da direita em sua ação agressiva contra os direitos sociais tão duramente conquistados nas últimas décadas pelas classes trabalhadoras.

O cenário atual do Brasil está marcado pelo crescimento da presença de amplos setores da direita nas ruas, disputando o apoio da população para os seus temas conservadores e autoritários.
Essa direita tem demonstrado força e tem pautado o debate político. Ancorada no resultado das eleições de 2014 que conferiu ao Congresso Nacional e às políticas governamentais um caráter conservador e autoritário a ofensiva da direita coloca em questão o exercício da democracia no Brasil.

\section{2}

\section{DEMOCRACIA, E IMPERIALISMO:} compatibilidades

AUTORITARISMO contradições e

A relação da democracia com o capitalismo é um dos temas mais recorrentes e polêmicos na Ciência Política. A facilidade com que a defesa da democracia aparece nos discursos de amplos setores, tanto à direita quanto à esquerda, reforça o caráter ambíguo e a multiplicidade de significados que tem a democracia.

Historicamente o debate sobre a compatibilidade ou não da democracia com o capitalismo atinge sua importância no século XIX com o avanço das lutas das classes trabalhadoras e com a formação dos Estados liberais. Bobbio (2000, p. 42-43) identifica o encontro do liberalismo com a democracia no momento em que esta é "[...] tomada não pelo lado de seu ideal igualitário, mas pelo lado de sua fórmula política, que é [...] a soberania popular", ou seja, a participação do maior número de cidadãos direta ou indiretamente nas decisões políticas coletivas. E defende que a única forma de se chegar a um consenso sobre o que seja um regime democrático é considerar a democracia como

[...] um conjunto de regras (primárias $e$ fundamentais) que estabelecem quem está autorizado a tomar as decisões coletivas e com quais procedimentos. (BOBBIO, 1986, p. 18).

Na década de 1940, Schumpeter (1984) desenvolve sua concepção de democracia pluralista. Compreende-a como um método de escolha e autorização de governos, como um

[...] acordo institucional para se chegar a decisões políticas em que indivíduos adquirem poder de decisão através de uma luta competitiva pelos votos da população. (SCHUMPETER, 1984, p. 336).

Nessa concepção, a participação política está limitada àqueles grupos auto-escolhidos para a função de direção do processo político, ou seja,

[...] o papel do povo é produzir um governo, ou melhor, um corpo intermediário que, por sua vez, produzirá um governo ou um executivo nacional. (SCHUMPETER, 1984, p. 336). 
Dahl (1996) atualiza as elaborações de Schumpeter ao considerar como critério para a identificação de um regime democrático o processo de eleição da elite dirigente. Seu interesse era

[...] chegar a uma acomodação entre o poder das maiorias e o das minorias, entre a igualdade política de todos os cidadãos adultos, por um lado, e o desejo de Ihes limitar a soberania, pelo outro. (DAHL, 1996, p. 13).

Para haver o equilíbrio político e garantir a estabilidade do sistema é necessário o consenso sobre a legitimidade das regras estabelecidas. Não há a preocupação em garantir uma maior participação política. Na verdade, essa ampliação é considerada um risco para o sistema, daí a restrição da participação ao período de eleição ao executivo e ao legislativo.

Portanto, os limites da participação política estão inscritos no próprio modelo e qualquer tentativa de ampliá-la ou questionar as decisões da chamada elite dirigente é reprimida com violência, como única alternativa de manter as regras do jogo de dominação da classe dominante. Arblaster (1987, p. 88, grifo do autor) esclarece que

[...] a própria definição de democracia foi revista, adaptada, limitada e diluída para tornar compatível com a convicção persistente da necessidade ou da virtude do governo das elites, com uma desconfiança igualmente persistente em relação às "massas", e talvez e mais importante de tudo, para a tornar compatível com os sistemas políticos existentes no mundo ocidental que se intitulam de "democracias".

No século XX, a partir da década de 1960, o mundo conheceu vários movimentos sociais que questionaram a concepção de democracia restrita à participação no processo eleitoral e introduziram a necessidade de vinculá-la ao processo de diminuição das desigualdades sociais. Compreenderam que a desigualdade social é estrutural no modo de produção capitalista e que a democracia liberal reproduz essa desigualdade no campo político e social.

Os movimentos sociais que eclodiram nas primeiras décadas do século XXI reafirmaram as denúncias da década de 1960. Milhares de pessoas organizados em movimentos como o Occupy Wall Street (OWS) nos EUA, os indignados na Espanha e as manifestações de junho de 2013 no Brasil foram às ruas para expressarem sua indignação às políticas neoliberais e exigiram respeito aos direitos sociais e políticos e mudanças na política econômica.

Pressionaram a democracia burguesa que respondeu com violência policial em todos os países. A ação foi unificada, os Estados nacionais utilizaram um forte aparato policial e jurídico para reafirmarem que não tolerariam qualquer questionamento a política econômica mesmo que nessa ação a face classista e autoritária da democracia burguesa ficasse evidente.

A forte repressão às manifestações contra as políticas neoliberais deixou claro que a ampliação dos espaços de liberdade depende dos interesses políticos e materiais da burguesia, que em situação de pressão, nega o seu discurso de liberdade, ou como escreveu Marx (1982, p. 214):

\section{[...] assim, desde que a palavra liberdade seja respeitada e que apenas a sua efetivação seja proibida, pelas vias legais, é claro, a existência constitucional da liberdade mantém-se integral, intacta, embora a sua existência real seja totalmente sufocada.}

$\mathrm{Na}$ atual fase do imperialismo e da financeirização da economia, os Estados nacionais tem encontrado dificuldades de disfarçar o caráter autoritário da democracia burguesa. O discurso ideológico da igualdade e da liberdade encontra sua negação no processo de exploração da força do trabalho. O aumento da pobreza, dos conflitos no campo, da precarização do trabalho, dos conflitos étnicos e religiosos possibilita que esse discurso seja desmistificado. A elaboração de Marx (1989, p. 196-197) nos permite compreender que
A esfera [...] da circulação ou da troca de mercadorias, dentro da qual se operam a compra e a venda da força de trabalho, é realmente um verdadeiro paraíso dos direitos inatos do homem. Só reinam aí liberdade, igualdade, propriedade e Bentham. Liberdade, pois o comprador e o vendedor de uma mercadoria, a força de trabalho, por exemplo, são determinados apenas pela sua vontade livre. Contratam como pessoas livres, juridicamente iguais. $\mathrm{O}$ contrato é o resultado final, a expressão jurídica comum de suas vontades. Igualdade, pois estabelecem relações mútuas apenas como possuidores de mercadorias e trocam equivalente por equivalente. Propriedade, pois cada um só dispõe do que é seu. Bentham, pois cada um dos dois só cuida de si mesmo. [...] Ao deixar a esfera da circulação simples ou da troca de mercadoria [...] o antigo dono do dinheiro marcha agora à frente como capitalista; segue-o o proprietário da força de trabalho como o seu trabalhador.

A política imperialista dos EUA ${ }^{2}$ é paradigmática como exemplo desse autoritarismo ao intervir na política interna dos países para garantir que seus interesses não sejam contrariados. Os exemplos são muitos, mas podemos ficar somente na América Latina, que passou por regimes militares 
apoiados pelos EUA e cuja democratização teve o monitoramento e a garantia de que o aparato repressor formado durante essas ditaduras não fosse desmantelado. No caso do Brasil, é esse aparato, formado durante o regime ditatorial e aprimorado nos últimos anos, que hoje é usado para reprimir as manifestações das classes populares.

Nesse início do século XXI os EUA tem tentado desestabilizar governos de esquerda ou de centro-esquerda que foram eleitos com uma política de independência frente ao seu domínio na região. A política dos EUA ${ }^{3}$ é fortalecer no interior de cada país, os setores de direita para empreenderem uma oposição e provocarem golpes institucionais, como podemos destacar as ações de interferência ocorridas na Bolívia, Venezuela, Paraguai, Equador ${ }^{4}$, Haiti ${ }^{5}$.

Na Bolívia, a eleição de Evo Morales em 18 de dezembro de 2005 , oriundo das lutas sociais dos povos indígenas e com uma campanha eleitoral de crítica às políticas neoliberais e aos EUA, deu origem a uma série de articulações da extrema direita para desestabilizar o governo e derrubar o presidente eleito. Todas elas com o apoio do governo norte americano. A ação mais grave foi o levante violento entre a extrema direita e os apoiadores do presidente que ocorreu nas províncias do Leste, por conta do reverendo da Constituição em 8 de agosto de 2008 e das eleições em que Evo Morales ${ }^{6}$ saiu mais uma vez vitorioso com $67 \%$ de aprovação.

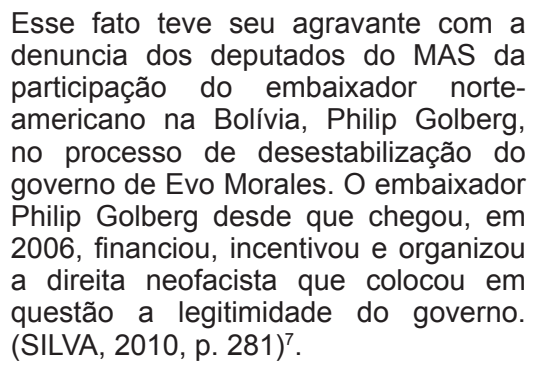

Na Venezuela a interferência dos EUA no fortalecimento da extrema direita foi direcionada para desestabilizar os governos de Hugo Chaves $^{8} \mathrm{e}$, mais recentemente, de Nicolás Maduro. O presidente Maduro denunciou que desde 2013, quando assumiu o governo já sofreu várias tentativas de golpe, causando uma grande instabilidade política em seu governo que é agravada pela crise econômica (WELLE, 2015). A oposição, que tem se alimentado da crise econômica provocada principalmente pela queda do preço do petróleo e pelas sanções dos EUA, torna-se cada vez mais audaciosa na conspiração contra o governo. As manifestações da direita levou o governo a realizar, em fevereiro de 2015, a prisão do prefeito de Caracas, Antonio Ledezma9 . Em março de 2015 o presidente Obama publicou um decreto que considera a Venezuela ${ }^{10}$ uma ameaça à segurança do país e inimigo dos EUA.
No Paraguai, o processo de impeachment no Congresso Nacional contra o presidente Fernando Lugo, foi relâmpago. No dia 22 de junho de 2012 os partidos conservadores conseguiram aprovar no Senado, com ampla maioria, o afastamento do presidente. Praticamente tudo ocorreu sem direito a defesa e sem debate com a população. Os motivos do impeachment estão relacionados a postura do governo diante dos conflitos com trabalhadores rurais em terra e a rapidez do processo foi justificada pelo suposto receio de Fernando Lugo mobilizar sua base e provocar conflitos violentos.

No Brasil a presença do imperialismo norte americano tem sido marcante e danosa para nossa soberania e economia ao longo dos anos. Nesse texto, nos interessa destacar a proximidade do PSDB com os interesses dos EUA, estreitados durante o governo do presidente Fernando Henrique Cardoso. A política econômica pró Estados Unidos garantiu o domínio político da grande mídia e o apoio financeiro às campanhas eleitorais do PSDB. Durante o governo de FHC, o Brasil cumpriu com as orientações do FMI e abriu o mercado através das privatizações das empresas estatais para o capital norte americano. Na política externa priorizou a criação da ALCA em detrimento de uma maior integração com os países do MERCOSUL.

Essa proximidade com os EUA foi amenizada com a eleição de LULA a presidência da república em 2002. Embora timidamente, os governos do Partido dos Trabalhadores (PT) se voltaram para uma articulação com os países latinos americanos e os países emergentes, investiram no MERCOSUL e na formação dos BRICS e ficaram simpáticos a proposta da ALBA, encaminhada pela Venezuela.

Os interesses políticos dos EUA no Brasil ficaram mais explícitos durante a campanha eleitoral de 2014 em que as frações da classe dominante pró-Estados Unidos se concentraram em apoiar o candidato do PSDB, Aécio Neves e empreenderam uma forte campanha ideológica contra Cuba e a Venezuela. Inconformados com a derrota eleitoral, essa direita postou dois dias após as eleições uma petição (POSITION..., 2014) no portal da We The People, da Casa Branca solicitando do presidente Obama medidas para barrar o crescimento do comunismo e da revolução bolivariana pelo governo Dilma Rousseff.

Muitos outros exemplos podem ser dados que evidenciam as ações do imperialismo norteamericano na América Latina. Suas táticas são variadas e específicas para cada pais. De modo geral, são utilizadas desde a ocupação militar, bloqueios econômicos, reforço à oposição conservadora para desestabilizar governos independentes ou críticos, até a destruição de movimentos sociais antiimperialistas. 
3 A AGENDA CONSERVADORA NO BRASIL: perspectivas

O padrão conservador e autoritário da política brasileira foi discutido por autores de variadas áreas do conhecimento. Para Florestan Fernandes (1973) o que caracteriza o desenvolvimento capitalista dependente dos países da América Latina é a articulação da industrialização em grande escala com a intensificação da arcaização do moderno. $\mathrm{Na}$ esfera política, as classes dominantes mantiveram as práticas autoritárias como forma de garantir seus privilégios o que tornou frágil e sob tensão as experiências de democratização. Por esse motivo,

[...] à medida que os interesses, as posições e as formas de solidariedade das classes "altas" e "médias" se viram ameaçadas pela classificação, mobilidade social e violência dos setores assalariados, pobres ou despossuídos, passou-se da conciliação para o endurecimento. (FERNANDES, 1973, p. 105, grifos do autor).

No Brasil, nossa formação sócio-histórica tem como traço estrutural essas práticas autoritárias. Nossa república nasce pelas mãos dos militares e com a exclusão dos setores populares. A concepção hegemônica de nação não incorporou a participação do negro e do índio na comunidade nacional. Os momentos de ascensão do movimento sindical e popular foram interrompidos por períodos ditatoriais. Em nossa curta experiência republicana tivemos 29 anos de ditaduras, o Estado Novo (1937-45) e a ditadura civil-militar (1964-85), intercalados por períodos de democracia restrita e sem rompimento com os instrumentos autoritários.

A ideologia do medo, que justifica e legitima as práticas autoritárias e a agenda conservadora de preservação da família tradicional e da propriedade, se renova a cada período de reorganização política dos setores populares. O processo de ampla mobilização de massas que teve como principal bandeira a democratização do Estado e que resultou, em 1988, na promulgação da chamada Constituição Cidadã não conseguiu mudar a prática autoritária do Estado brasileiro e de omissão diante dos assassinatos de lideranças dos movimentos sociais, dos processos de grilagem de terras indígenas e quilombolas, de ameaças e prisões de manifestantes. Pelo contrário, o Estado brasileiro continua sendo o principal articulador da violência contra as classes populares que saem às ruas para reivindicarem melhorias das condições de vida e denunciarem as políticas neoliberais.

Desde a década de 1980 que o debate sobre a democracia assumiu o centro da agenda política no Brasil. O discurso da democratização tem ecoado nas ruas sustentado por setores tanto à direita e quanto à esquerda. Essa multiplicidade de concepção provoca a necessidade de aprofundarmos a discussão teórica sobre a democracia, principalmente no aspecto de sua funcionalidade para a reprodução das relações capitalistas e de domínio da ideologia burguesa da igualdade e da liberdade.

A década de 1990 se inicia com a ascensão do neoliberalismo e com o discurso de exaltação do mercado como espaço privilegiado de exercício da liberdade, ao mesmo tempo em que se atacava e se desmontava as tímidas políticas sociais conquistadas pelos movimentos sociais da década de 1980. Nesse período, o setor conservador se rearticula rapidamente e tem na figura do então presidente da república Fernando Henrique Cardoso, do PSDB, seu principal interlocutor. A reforma do aparelho de Estado ${ }^{11}$ encaminhada pelo governo federal em 1995, que apresentava como principal objetivo a democratização e a modernização do Estado brasileiro, rompeu com a perspectiva universalizante, pública e estatal das políticas sociais inscritas no texto constitucional de 1988 e restringiu a participação das classes populares no processo decisório dessas políticas.

Os governos do PT, iniciados com o presidente Luís Inácio Lula da Silva, em 2002, não interromperam esse processo, em que pese as políticas de combate a pobreza. Esses governos mantiveram a agenda neoliberal e não enfrentaram problemas estruturais importantes como a reforma agrária e o modelo de desenvolvimento.

O resultado das eleições de $2014^{12}$ em que a presidente Dilma Rousseff venceu com uma margem muito pequena de votos, expressou a polarização política em que o país mergulhou nesses últimos anos de crescimento dos setores conservadores. A composição do Congresso Nacional é paradigmática a esse respeito. As chamadas bancadas ruralista, da bala e evangélica cresceram na mesma medida em que diminuiu o número de deputados ligados aos setores sindicais, aos partidos de esquerda e aos trabalhadores rurais $^{13}$. Na sociedade civil o que se observa é o crescimento da intolerância com o aumento dos assassinatos de homossexuais, de invasões a terreiros da religião afro-brasileira e da violência doméstica.

Os setores das classes dominantes não tem se contentado apenas com a implementação da agenda neoliberal, desejam ocupar diretamente o executivo federal e conquistar o apoio das massas para sua agenda conservadora. As manifestações de $2015^{14}$ em que a direita ocupou as ruas com bandeiras que incitavam o ódio às organizações de esquerda e aos comunistas, ao mesmo tempo em que realçavam o viés nacionalista são uma clara indicação dessa disputa. A ousadia da direita em apresentar bandeiras como chega de corrupção e intervenção militar já, impeachment: tira Dilma em ameaçar de morte João Pedro Stédile, líder do Movimento dos Trabalhadores Sem Tetos (MST), 
o ex-presidente Lula e a presidente Dilma Russeff, indicam que a agenda conservadora assumiu o centro da pauta política.

O presidente da Câmara dos Deputados, Eduardo Cunha do Partido do Movimento Democrático Brasileiro (PMDB/RJ) reabriu vários projetos de cunho conservador que foram aprovados sem grande oposição e com forte aparato policial de proteção aos deputados que se sentiram ameaçados pelos movimentos sociais que realizaram mobilizações em frente do Congresso Nacional. Os partidos de esquerda e as entidades sindicais e populares estão encontrando dificuldades de realizarem grandes mobilizações de massa para pressionarem os deputados a não votarem essa agenda. Os pontos da agenda conservadora ${ }^{15}$ são muitos, mas para os objetivos desse artigo destacamos apenas 4 dos projetos que foram votados na Câmara dos Deputados.

No dia 08 de abril de 2015 foi aprovado na Câmara dos Deputados o Projeto de Lei 4330/2004, conhecido como projeto da terceirização, que permite a contração de serviços terceirizados em qualquer atividade, seja no setor público como no privado (BRASIL, 2015c). Há 10 anos tramitando no Congresso, esse projeto intensifica a precarização do trabalho em vários setores e prejudica a formação da carreira no setor público. As entidades sindicais alertam que, na prática, o Projeto desobriga o gestor a abrir concursos públicos, enquanto privilegia as indicações políticas via terceirizadas e não investe na qualificação da força de trabalho, além de provocar uma diminuição nos salários ${ }^{16}$.

No dia 14 de agosto de 2015 foi aprovado pela Câmara dos Deputados com ampla maioria de votos a proposta de emenda constitucional, PEC 171/93, que reduz a maioridade penal (BRASIL, 2015a) de 18 para 16 anos para crimes hediondos, homicídios doloso, roubo qualificado e lesão corporal grave seguida de morte. Os inúmeros protestos das entidades de proteção à criança e ao adolescente, os estudos que indicam que a participação dos adolescentes nesses crimes não alcança nem $1 \%$ dos crimes praticados no Brasil, não foram suficientes para mudar os votos esses deputados.

A reforma política é outro tema bastante debatido no Congresso Nacional e instrumentalizado como mecanismo de combate a corrupção. Entretanto são muitos os discursos para que nada seja mudado. Os dois projetos que dão conta do tema, PEC n. 182, 23 de outubro de 2007 e o Projeto de Lei 5735 , de 6 de junho de $2013^{17}$, foram aprovados respectivamente no dia 07 de julho de 2015 e 09 de setembro de 2015, garante as doações de empresas aos partidos políticos em período eleitoral, estabelece o fim da reeleição, aumenta o mandato para cinco anos, diminui a idade mínima para deputado, senador e governador e instituiu uma clausula de barreira que prejudica os partidos menores, principalmente do campo da esquerda, dentre outras. Entretanto o projeto apresentado pela sociedade civil com a assinatura de mais de 800 mil pessoas e subscrito por mais de 100 entidades como a OAB, CNBB, CUT, Movimento de Combate a Corrupção Eleitoral (MCCE) e que faz críticas ao projeto aprovado não foi sequer apreciado pelos deputados.

Diante do avanço da agenda conservadora que não tem encontrado dificuldade no Congresso Nacional para ser aprovada, resta aos movimentos da classe trabalhadora o desafio de construir a unidade do campo da esquerda para organizar as massas na luta de resistência ao processo de negação dos direitos políticos e sociais. Em períodos de crise, a relação capital/Estado lança mão do aparelho repressor para impedir a luta dos trabalhadores enquanto garante que o processo de acumulação continue nos trilhos.

\section{REFERÊNCIAS}

ARBLASTER, A. Democracia. Lisboa: Estampa, 1987.

BOBBIO, N. Liberalismo e democracia. São Paulo: Brasiliense, 2000.

O futuro da democracia: uma defesa das regras do jogo. 6. ed.. Rio de Janeiro: Paz e Terra, 1986.

BRASIL. Câmara dos Deputados. Câmara aprova em $2^{\circ}$ turno redução da maioridade penal em crimes graves. Brasília, DF, 2015a. Disponível em:<http://www2.camara.leg.br/camaranoticias/ noticias/DIREITO-E-JUSTICA/494248-CAMARAAPROVA-EM - 2-TURNO-REDUCAO-DAMAIORIDADE-PENAL-EM-CRIMES-GRAVES. html>. Acesso em: 21 jun. 2015.

Câmara dos Deputados. Câmara aprova reforma política em $2^{\circ}$ turno; falta votar destaques. Brasília, DF, 2015b. Disponível em:<http://www2.camara.leg.br/camaranoticias/ noticias/POLITICA/491873-CAMARA-APROVAREFORMA-POLITICA-EM-2-TURNO-FALTAVOTAR-DESTAQUES.html>. Acesso em:

Senado Federal. Entenda o projeto da terceirização (PL 4.330). Brasília, DF, 2015c. Disponível em:<http://www12.senado.leg.br/ noticias/materias/2015/04/27/quadro-pl-4.330>. Acesso em: 21 jun. 2015.

CRÍTICAS ao projeto de terceirização marcam debate no Senado. Vermelho Portal, São Paulo, 2015. Disponível em:<http://www.vermelho.org.br/ noticia/262184-1>. Acesso em: 21 jun. 2015. 
DAHL, R. A. Um prefácio à teoria democrática. Rio de Janeiro: Zahar. 1996

EVO Morales expulsa agência norte-americana da Bolívia. O Estado de São Paulo, São Paulo, 2013. Disponível em:<http://internacional.estadao.com.br/ noticias/geral,evo-morales-expulsa-agencia-norteamericana-da-bolivia,1027417>. Acesso em: 19 jun. 2015.

FERNANDES, F. Capitalismo dependente e classes sociais na América Latina. Rio de Janeiro: Zahar, 1973

GUERREIRO, G. Comissão liderada por Aécio viajar a Venezuela por opositores presos. Folha de São Paulo, São Paulo, 2015. Disponivel em:<http:// www1.folha.uol.com.br/mundo/2015/06/1642404comissao-liderada-por-aecio-viaja-a-venezuela-poropositores-presos.shtml>. Acesso em: 19 jun. 2015.

MANIFESTAÇÕES contra Dilma ocorrem em todos os estados do Brasil. G1, São Paulo, 2015. Disponível em:<http://g1.globo.com/politica/ noticia/2015/12/manifestacoes-por-impeachmentde-dilma-sao-registradas-pelo-brasil.html>. Acesso em: 19 jun. 2015

MARX, K. O 18 Brumário de Louis Bonaparte. In: ENGELS, F. Obras Escolhidas. v. 1. São Paulo: Alfa-Omega, 1982.

O Capital. 12. ed. Rio de Janeiro: Bertrand, 1989. Livro I, v. II.

POSITION yourself against the Bolivarian communist expansion in Brazil promoted by the administration of Dilma Rousseff. We the People, [S. I.], 2014. Disponível em:<https://petitions. whitehouse.gov/petition/position-yourself-againstbolivarian-communist-expansion-brazil-promotedadministration-dilma-rousseff>. Acceso en: 21 jun. 2015

SCHUMPETER, J. A. Capitalismo, socialismo e democracia. São Paulo: Zahar. 1984.

SILVA, I. G. Democracia e participação na reforma do Estado. São Paulo: Cortez, 2002.

Lutas Sociais na Bolívia e o protagonismo dos movimentos antissistêmicos. Revista de Políticas Públicas, São Lupis, n. esp., p. , ago. 2010.

WELLE, D. Unasul nega omissão em crise na Venezuela. Carta Capital, São Paulo, 2015. Disponível em:<http://www.cartacapital.com.br/ internacional/unasul-nega-omissao-em-crise-navenezuela-3913.html>. Acesso em: 19 jun. 2015.

\section{NOTAS}

Veja a cronologia da greve na Gazeta do Povo (Disponível em:<http://www.gazetadopovo.com.br/vidae-cidadania/cronologia-bxyes24fyo4r7knblzc9uzrut $>$. Acesso em: 13 nov. 2014)

2 PETRAS nos oferece vários exemplos da interferência dos EUA na política interna dos países, desestabilizando seus regimes políticos. Sugiro a leitura de Democracia y autoritarismo: transición democrática o neoautoritarismo (Disponível em:<http://www.herramienta.com.ar>. Acesso em: 13 nov. 2014)

$3 \quad$ A $7^{\text {a }}$. Cúpula das Américas, no Panamá, em 10 de abril de 2015 foi marcada pelas denúncias contra os Estados Unidos em suas tentativas de desestabilizar os governos da Bolívia, Cuba, Venezuela, Brasil e Argentina. Evos Morales denuncia ação desestabilizadora dos EUA conta a América Latina. Disponível em:<http:/ www. rededemocratica.org/index.php?option $=\mathrm{com}$ k2\&view=item\&id=7554:evo-morales-denuncia-aa\% C3\%A7\%C3\%A3o-desestabilizadora-dos-euacontra-a-america-latina>. Acesso em: 19 jun. 2015.

No Equador o Presidente Rafael Correa expulsou a embaixadora dos EUA por interferir nos assuntos internos do país, em abril de 2011.

5 O golpe militar no Haiti ocorreu em fevereiro de 2004 que derrubou o presidente Jean-Bertrand Aristides, eleito em 2001

6 No 10 de maio de 2013 o presidente Evo Morales expulsou da Bolívia a Agência dos Estados Unidos para o Desenvolvimento Internacional (USAID) sob a acusação de conspiração contra o seu governo (EVO..., 2013).

Por conta da comprovação da conspiração o embaixador Philip Golbergfoi expulso da Bolívia. Para maiores informações sugiro a leitura de Silva (2010).

Hugo Chaves foi eleito presidente da Venezuela várias vezes, a primeira ocorreu em 1998, e posteriormente em 2002, 2006, 2012. Seu governo foi marcado por forte posição antiimperialista e contra as políticas neoliberais e os EUA. Em 11 de abril de 2002 sofreu um golpe de Estado que durou 47 horas. Após o golpe de Estado assumiu a presidência da república Pedro Carmona, na época presidente da maior organização empresarial - Federação Venezuelana de Câmaras de Comércio (FEDECÂMARAS). O novo governo teve reconhecimento imediato dos EUA. Chaves morreu em 2013.

9 A prisão do prefeito de Caracas, Antonio Ledezma, provocou a reação dos partidos de oposição ao governo Dilma, que exigem que o Brasil imponha medidas contra a Venezuela, retirando-a do Mercosul, sob a acusação de violar a democracia. Líderes do PPS, PSDB e DEM organizaram comitiva e viajaram para Caracas para prestarem solidariedade a Antonio Ledezma (GUERREIRO, 2015).

10 Nas eleições para a Assembleia Nacional, em dezembro de 2015, a direita venceu com o Mesa da Unidade Democrática (MUD) ao eleger 112 deputados correspondente a $2 / 3$ da Assembleia, enquanto 0 Partido Socialista Unido da Venezuela elegeu somente 51 deputados. 
11 Para esse tema sugiro a leitura de Silva (2002).

12 Nas eleições presidenciais de 2014 a candidata do PT, Dilma Rousseff atingiu $51,54 \%$ dos votos, enquanto o candidato do PSDB, Aécio Neves 48,16\%.

13 Sugiro a leitura do levantamento feio pelo Departamento Intersindical de Assessoria Parlamentar (DIAP) intitulado Radiografia do Novo Congresso: Legislatura 2015-2019 - Brasília, DF, 2014, 164 p.: il.; color. (Estudos Políticos do DIAP).

14 As principais manifestações da direita durante o ano de 2015 foram no dia 15 de março com cerca de 1 milhão de pessoas em 26 estados, 16 de agosto com 879 mil e 13 de dezembro com 83 mil pessoas em 26 estados (MANIFESTAÇÕES..., 2015).

15 Podemos incluir na agenda conservadora o projeto $6583 / 13$ que institui o Estatuto da Família limitando a concepção de família ao agrupamento composto por um homem, mulher e filhos; as mudanças nas regras do seguro desemprego e do reajuste do salário mínimo; as mudanças no Estatuto do Desarmamento e o projeto que garante a independência do Banco Central.

16 O Departamento Intersindical de Estatística e Estudos Sócio-econômicos (Dieese) informa que as terceirizadas são responsáveis pela maioria dos trabalhadores resgatados da condição de escravidão, pela maioria dos acidentes de trabalho com óbitos, pela grande rotatividade no mercado de trabalho (CRÍTICAS..., 2015).

17 A presidente Dilma Rousseff, seguindo orientação do Supremo Tribunal Federal, vetou o artigo do respectivo Projeto de Lei que autorizava o financiamento empresarial. Em sessão do dia 18/11/2015 o Congresso Nacional manteve o voto da presidente (BRASIL, 2015b).

\section{Ilse Gomes Silva}

Enfermeira

Mestre em Políticas Públicas pela UFMA e Doutora em Ciências Sociais - Política pela PUC/SP

Professora de Ciência Política da Universidade Federal do Maranhão (UFMA)

E-mail: ilse@terra.com.br

\section{Universidade Federal do Maranhão - UFMA}

Cidade Universitária Dom Delgado

Av. dos Portugueses, n. 1966, Bacanga, São Luís/MA

CEP: $65085-580$ 